\title{
Tissue-engineered sling with adipose-derived stem cells under static mechanical strain
}

\author{
YING WANG $^{1}$, WEI WANG ${ }^{1}$, XILONG WANG $^{1}$, YANGYUN WANG $^{1}$, \\ JIHONG WANG ${ }^{2}$, QIANG FU ${ }^{2}$ and GUOWEI SHI ${ }^{1}$ \\ ${ }^{1}$ Department of Urology, The Fifth People's Hospital of Shanghai, Fudan University, Shanghai 200240; \\ ${ }^{2}$ Department of Urology, Shanghai Jiao Tong University Affiliated Sixth People's Hospital, Shanghai 200233, P.R. China
}

Received April 11, 2016; Accepted March 17, 2017

DOI: $10.3892 / \mathrm{etm} .2017 .4705$

\begin{abstract}
The implantation of a suburethral sling is an important treatment for stress urinary incontinence (SUI). However, the slings used current have a number of inherent limitations, such as tissue rejection and infection. The present study investigated the potential of engineering sling tissue in vitro using adipose-derived stem cells (ADSCs). The ADSCs were obtained from Sprague-Dawley rats and were characterized in vitro. The ADSCs were seeded on polyglycolic acid (PGA) fibers that formed a scaffold with a shape mimicking a sling complex. The results demonstrated that following in vitro culture for 12 weeks under static strain, neo-sling tissue could be generated using ADSCs. With increasing culture time, the engineered neo-sling tissue exhibited a significant improvement in biomechanical properties, including maximal load and Young's modulus $(\mathrm{P}<0.05)$, and the tissue and collagen structures matured. Furthermore, differentiated ADSCs cultured under static strain were maintained their myoblast phenotype within the PGA scaffolds. These results indicate that ADSCs may serve as a novel cell source for tissue sling engineering and could improve treatment for patients with SUI.
\end{abstract}

\section{Introduction}

Stress urinary incontinence (SUI) is a common and embarrassing urologic problem $(1,2)$. Among the various treatment techniques available, the sling procedure has become the mainstay of surgical treatment for the management of SUI.

Correspondence to: Professor Qiang Fu, Department of Urology, Shanghai Jiao Tong University Affiliated Sixth People's Hospital, 600 Yishan Road, Shanghai 200233, P.R. China

E-mail: jamesqfu@aliyun.com

Professor Guowei Shi, Department of Urology, The Fifth People's Hospital of Shanghai, Fudan University, 801 Heqing Road, Shanghai 200240, P.R. China

E-mail: drsgw@189.cn

Key words: adipose-derived stem cells, polyglycolic acid, sling, tissue engineering, stress urinary incontinence
However, these slings are associated with complications, including infection and urethral erosion (3-6). Following the advancements in tissue engineering research, a biodegradable tissue engineered sling may offer a promising alternative for the treatment of SUI $(7,8)$.

Over the past 10 years, numerous studies have reported injectable stem cell therapies that achieved a high success rate in repairing SUI models. Muscle-derived stem cells (9), adipose-derived stem cells (ADSCs) $(10,11)$, bone-marrow-derived mesenchymal stem cells (BMSCs) (12), fibroblasts and myoblasts (13) have been used for the repair of damaged sphincter muscle, which reveals a promising approach for sling engineering in vitro.

In the present study, a polyglycolic acid (PGA) scaffold was selected as the suburethral sling material because of its good biocompatibility and suitable degradation rate (14). Considering the fact that the majority of sling engineering studies have reported the short-term results of in vivo sling engineering, ADSCs and PGA were employed to explore the possibility of generating a sling complex in vitro for a relatively longer observation period. In future, it would be optimal to provide off-the-shelf engineered sling products so that patients can benefit from sling grafts that are immediately available.

\section{Materials and methods}

Isolation and culture of ADSCs. The Sprague-Dawley rats were obtained from the Animal Research Center of Fudan University (Shanghai, China). A total of 20 4-month-old female Sprague-Dawley rats (body weight, $240 \pm 20 \mathrm{~g}$ ) were housed in pairs at $23^{\circ} \mathrm{C}$ and $50-70 \%$ humidity, with a $12 \mathrm{~h} \mathrm{light/dark}$ cycle and free access to water and food pellets. Adipose tissues were obtained from the inguinal regions of Sprague-Dawley rats. The experimental protocol was approved by the Research Ethics Committee of the Shanghai Jiao Tong University Affiliated Sixth People's Hospital (Shanghai). Isolation and culture of ADSCs was performed as described previously $(15,16)$. Briefly, the samples were digested with $0.10 \%$ collagenase I (Sigma-Aldrich, Inc.; Merck KGaA, Darmstadt, Germany) through shaking at $37^{\circ} \mathrm{C}$ for $1 \mathrm{~h}$. Following digestion, collagenase I was neutralized with an equal volume of basic growth medium containing Low Glucose Dulbecco's Modified Eagle's Medium (LG-DMEM; HyClone; GE Healthcare 
Life Sciences, Logan, UT, USA) supplemented with $10 \%$ fetal bovine serum (FBS) and 1\% penicillin/streptomycin (both Gibco; Thermo Fisher Scientific, Inc.). After centrifugation at $37^{\circ} \mathrm{C}$ for $5 \mathrm{~min}$ at $1,500 \mathrm{x} \mathrm{g}$, cells were resuspended in the basic growth medium and cultured at $37^{\circ} \mathrm{C}$ with $5 \% \mathrm{CO}_{2}$. The culture medium was changed every 3 days. When the culture dishes reached $80-85 \%$ confluence after $\sim 4$ days, the cells were passaged with trypsin-EDTA. ADSCs at passage 2 were used for the following experiments.

Characterization of ADSCs in vitro. The specific cell surface antigens, cluster of differentiation (CD) 90, 44 and 34, of ADSCs were characterized by flow cytometry analysis. Briefly, cells were incubated with fluorescein isothiocyanate-tagged antibodies, including anti-rat CD90 (1:100; cat. no. 11-0900; eBioscience; Thermo Fisher Scientific, Inc.), anti-rat CD44 (1:100; cat. no. MCA643FA; Bio-Rad Laboratories, Inc., Hercules, CA, ISA) and anti-rat CD34 (1:100; cat. no. 11-0341, eBioscience; Thermo Fisher Scientific, Inc.) for $30 \mathrm{~min}$ at $4^{\circ} \mathrm{C}$, then washed three times using PBS containing 4\% FBS. Flow cytometry was performed using fluorescence-activated cell sorting (FACSCalibur; BD Biosciences, Franklin Lakes, NJ, USA) according to the manufacturer's protocol. Data were analyzed by FlowJo software version 7.6 (Tree Star, Inc., Ashland, OR, USA). The ADSCs were cultured and induced using an appropriate medium. For osteogenic differentiation, ADSCs were induced in DMEM supplemented with $10 \%$ FBS, $\beta$-glycerol phosphate, dexamethasone and ascorbic acid for 3 weeks, and analyzed with Alizarin Red S staining as previously described $(17,18)$. For adipogenic differentiation, ADSCs were incubated in DMEM supplemented with $10 \%$ FBS, 1-methyl-3-isobutylxanthine, dexamethasone, insulin and indomethacin for 2 weeks, and analyzed by Oil Red O staining as previously described (19).

Preparation of cell-PGA constructs. A custom-made spring formed with a stainless steel frame was used to provide constant strain as described previously (20). Briefly, $50 \mathrm{mg}$ PGA fibers ( 20-30 $\mu \mathrm{m}$ in diameter) were arranged into a cord shape with a length of $4.5 \mathrm{~cm}$ and a diameter of $0.4 \mathrm{~cm}$, and then secured onto a custom-made spring. The scaffolds were sterilized with $75 \%$ ethanol, washed with PBS and then pre-incubated at $37^{\circ} \mathrm{C}$ in DMEM supplemented with $10 \%$ FBS to enhance cell attachment. Subsequently, the ADSCs were collected and resuspended in culture medium at a density of $4 \times 10^{7}$ cells $/ \mathrm{ml}$ followed by seeding onto the PGA fibers. After 7 days of culture, the cell-scaffold construct was examined using a scanning electron microscope (SEM) as reported previously (21). After the SEM examination, the subsequent culture period included a 4-week-long myoblast differentiation phase and an 8-week-long proliferation phase. Induction of myoblast differentiation was performed by adding $10 \mu \mathrm{mol} / 1$ 5-azacytidine (5-Aza, Sigma-Aldrich, Inc.; Merck KGaA), 5\% FBS and 5\% horse serum (Gibco; Thermo Fisher Scientific, Inc.) to LG-DMEM. After the 4-week-long differentiation phase, the medium was replaced with basal culture medium containing LG-DMEM supplemented with 10\% FBS.

Analysis of the cell scaffolds. At 4 weeks (following the 4-week-long myoblast differentiation phase), 8 weeks (4-weeks into the proliferation phase) and 12 weeks (following the 8 -week-long proliferation phase), specimens of in vitro engineered slings were collected, and their length and diameter was measured. Randomly selected samples were taken and fixed with $4 \%$ paraformaldehyde at $4^{\circ} \mathrm{C}$ for $24 \mathrm{~h}$ followed by three washes in PBS, prior to being paraffin embedded and sectioned to a 5-8 $\mathrm{mm}$ thickness for hematoxylin and eosin (HE) staining as reported previously (21) in order to examine the tissue structure, particularly the cellular density and rate of PGA degradation. In addition, the sections were subjected to Masson's trichrome staining as described previously (21) in order to examine collagen production. Myoblast formation was evaluated by immunohistochemical staining. The tissue sections were stained with primary antibodies directed against desmin (1:100; Abcam, Cambridge, UK) and $\alpha$-smooth muscle actin ( $\alpha$-SMA; 1:100), followed by the addition of a goat anti-rabbit secondary IgG conjugated to horseradish peroxidase (EnVision+ system; Dako; Agilent Technologies, Inc., Santa Clara, CA, USA). The antibody staining was visualized with the Liquid $\mathrm{DAB}^{+}$Substrate Chromogen system (cat. no. K3467; Dako; Agilent Technologies, Inc.) prior to counterstaining with hematoxylin at $37^{\circ} \mathrm{C}$ for $15 \mathrm{~min}$.

Biomechanical analysis. The in vitro engineered slings were collected at 4, 8 and 12 weeks as described above. The constructs were subjected to mechanical tests using a biomechanical analyzing instrument (Instron Model 4411; Instron, Norwood, MA, USA). The length of the tested slings was set to $2 \mathrm{~cm}$ between two grippers. The grippers were then gradually moved apart at a speed of $25 \mathrm{~mm} / \mathrm{min}$ until complete rupture of the tissue in order to calculate the maximal (max) load. Additionally, the Young's modulus (MPa) was calculated from the linear slope of a stress-strain curve as described previously (22).

Statistical analysis. All quantitative data are presented as the mean \pm standard deviation. A one-way analysis of variance was performed to analyze the differences in mechanical properties between different time points. $\mathrm{P}<0.05$ was considered to indicate a statistically significant difference. SPSS software (version 11.0; SPSS, Inc., Chicago, IL, USA) was used for all statistical analysis.

\section{Results}

Morphological and differentiation characteristics of ADSCs. Primary cultured ADSCs generated from fresh rat adipose tissue proliferated rapidly, reaching $80 \%$ confluence within 5 days. These cells were assessed for the expression of cell surface markers that are considered to define adult stem cells, and identified to express CD90 (Fig. 1A) and CD44 (Fig. 1B). However, the cells were negative for the hematopoietic stem cell marker CD34 (Fig. 1C). Additionally, ADSCs were tested for their ability to differentiate into other cell types. ADSCs cultured in adipogenic medium accumulated lipid vacuoles, which were confirmed by Oil Red O staining (Fig. 1D). Furthermore, ADSCs cultured in osteogenic medium deposited calcium as detected by Alizarin Red S staining (Fig. 1E). These data indicate that ADSCs exhibits multipotentiality. 

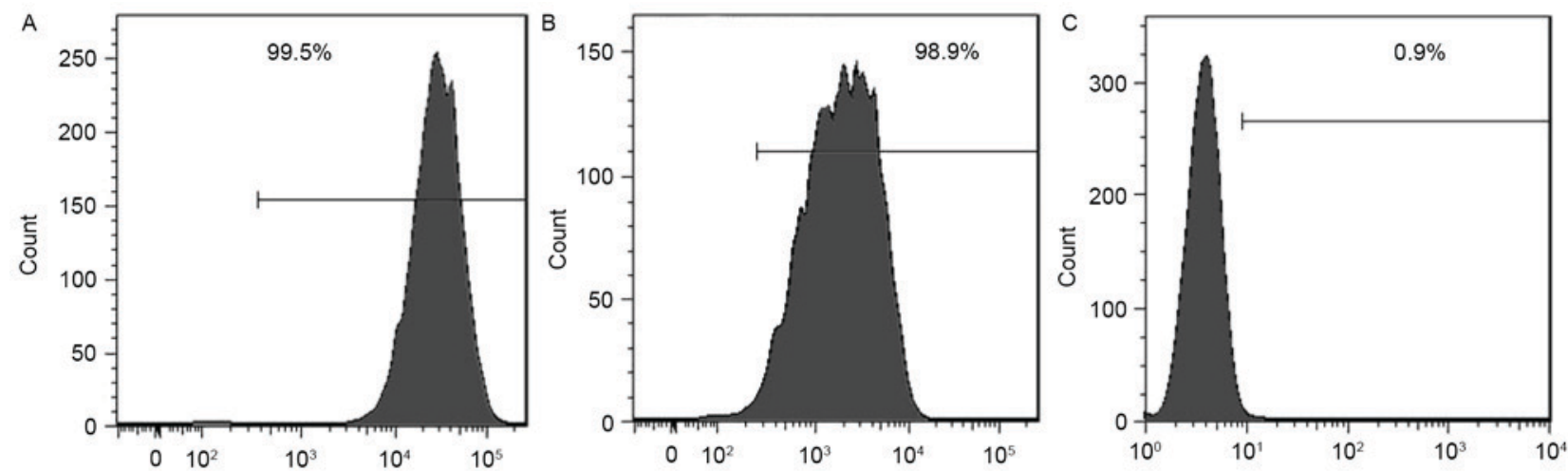

D

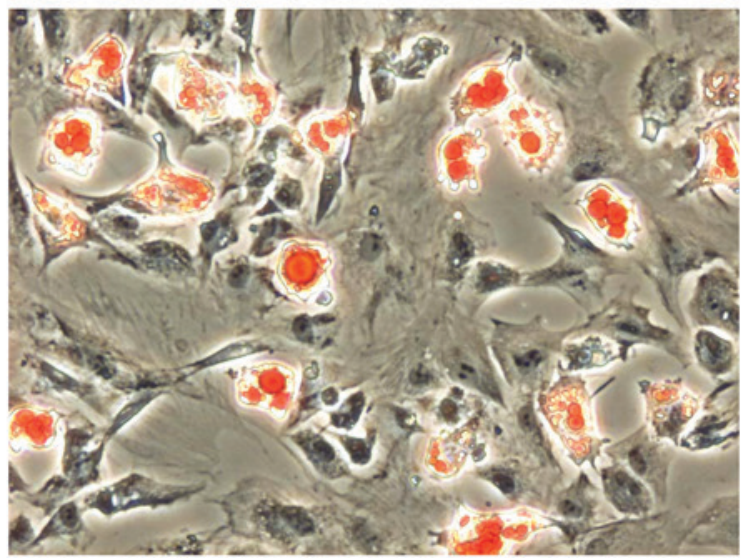

$\mathrm{E}$

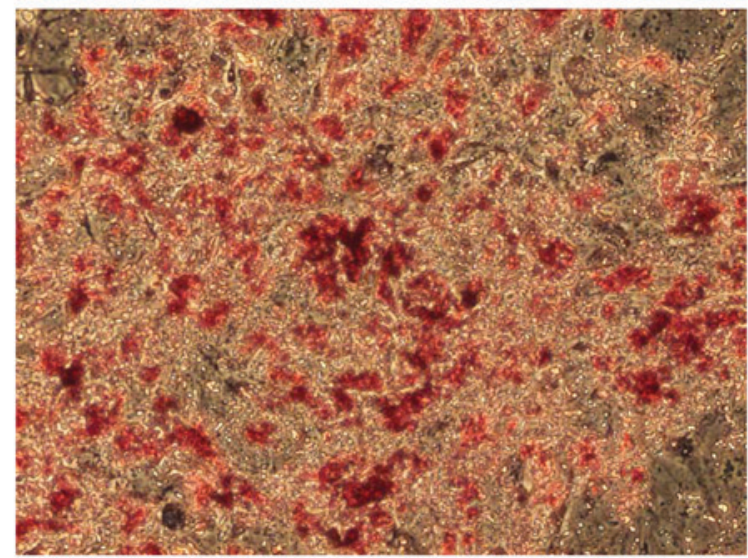

Figure 1. Characterization of the ADSC scaffolds. ADSC expression of (A) CD90, (B) CD44 and (C) CD34 was analyzed using flow cytometry. (D) Oil Red O staining revealed lipid vacuoles in the cytoplasm of the ADSCs. (E) Alizarin Red S staining revealed calcium deposits as red granules in the ADSC. Magnification, x100. ADSCs, adipose-derived stem cells; CD, cluster of differentiation.

Culture and characterization of the ADSC-PGA complex. At passage 2, the ADSCs were observed to be able to maintain good proliferation (Fig. 2A), and were thus used for sling engineering by seeding them onto a PGA scaffold under a constant strain (Fig. 2B). A total of 7 days after seeding, phase-contrast microscopy and SEM revealed good cell attachment on the scaffold and secreted extracellular matrices filling the space between the fibers (Fig. 2C and D), indicating good biocompatibility between the ADSCs and PGA fibers.

Grossobservation andmechanicalproperties of the engineered slings. As illustrated in Fig. 3A, the ADSC-PGA construct appeared as a sling-like structure with a cord-like shape during the first 4 weeks of in vitro culture. The engineered slings exhibited a smoother surface at 8 (Fig. 3B) and 12 (Fig. 3C) weeks of culture. However, at 12 weeks the sling-like structure became much thinner with a more mature tissue appearance when compared with the constructs at 4 weeks. Furthermore, a biomechanical analyzing instrument was used to examine the mechanical properties of the in vitro engineered slings. As presented in Fig. 3D-F, the engineered slings exhibited different patterns of stress/strain curves when they were subjected to mechanical testing at 4,8 and 12 weeks, respectively. In order to further associate tissue structure features and their mechanical properties in the slings, the max load and Young's modulus were investigated. After 4, 8, and 12 weeks of culture, the max load reached $0.26 \pm 0.02 \mathrm{~N}, 0.84 \pm 0.06 \mathrm{~N}$ and $1.05 \pm 0.06$ N, respectively (Fig. 3G). Furthermore, Young's modulus at 4
$(0.26 \pm 0.03 \mathrm{MPa}), 8(0.64 \pm 0.16 \mathrm{MPa})$ and 12 weeks $(0.94 \pm 0.11$ $\mathrm{MPa}$ ) increased with time (Fig. $3 \mathrm{H}$ ). These results demonstrate that the engineered slings had gradually increased stress/strain curves, max load and Young's modulus values over time, with significant differences between slings cultured for 4,8 and 12 weeks of culture $(\mathrm{P}<0.05)$.

Histological assessment of the in vitro engineered slings. The in vitro engineered slings were assessed by $\mathrm{HE}$ and Masson's trichrome staining (Fig. 4). This revealed that the ADSC-PGA constructs were primarily composed of PGA fibers, with less matrix deposition observed at 4 weeks of culture (Fig. 4A and D). When cultured for 8 weeks, the slings exhibited a structure of longitudinally aligned collagen fibers and cells with increased matrix deposition (Fig. 4B and E). At 12 weeks, the parallel alignment of the cells and collagen fibers was enhanced further (Fig. 4C and F), suggesting that a longer cultivation enhances tissue remodeling and maturation. To further investigate whether ADSCs could be induced to differentiate into myoblasts and whether the differentiated ADSCs could maintain their contractile phenotype when seeded onto the PGA scaffold, immunohistochemical staining for desmin and $\alpha$-SMA was performed. As illustrated in Fig. 4G-L, the tissue of the engineered slings was identified to contain cells expressing desmin and $\alpha$-SMA, which increased over time. Complete degradation of the scaffold material was identified after 12 weeks of culture (Fig. 4C and F). 
A

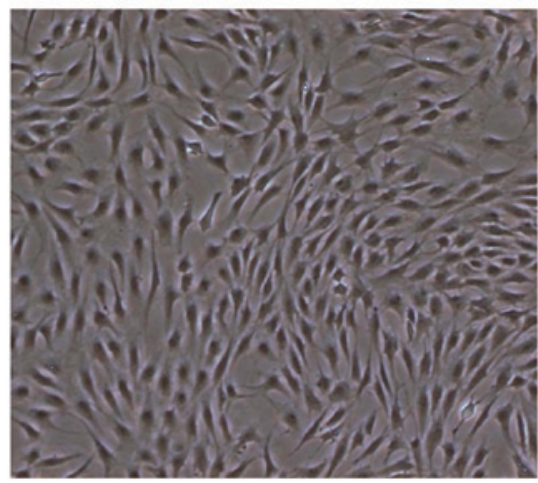

C

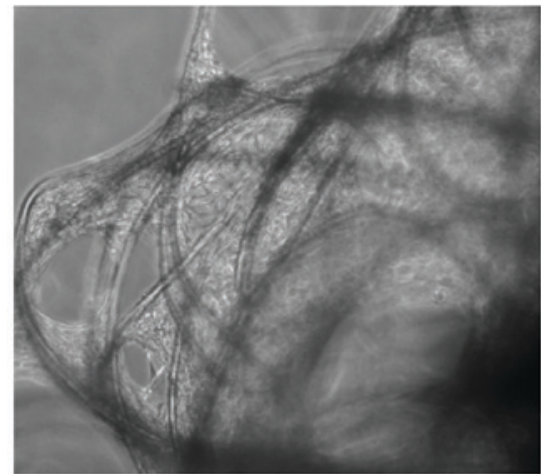

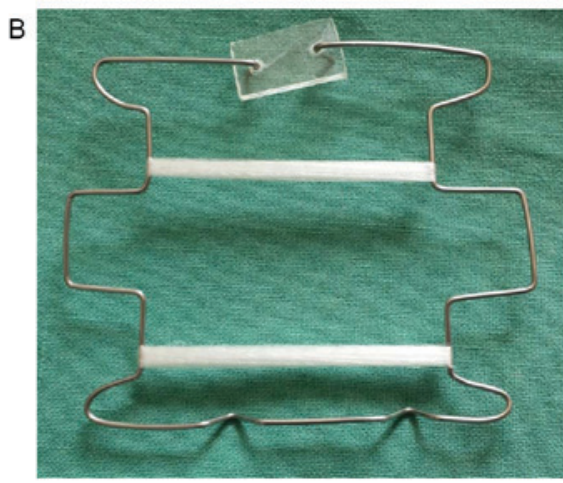

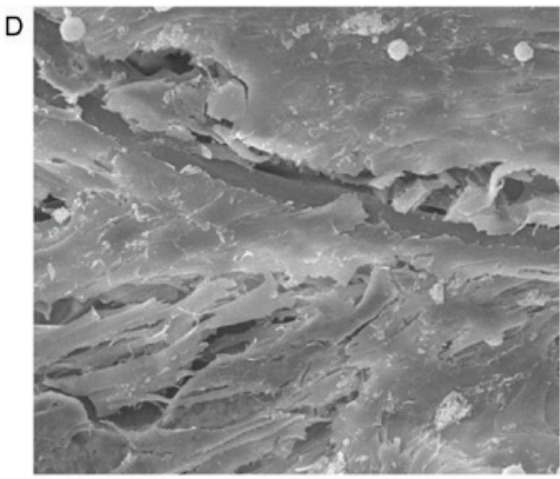

Figure 2. In vitro culture of the ADSC-PGA constructs. (A) ADSCs cultured for 3 days. Magnification, x40. (B) PGA scaffold secured onto a custom-made stainless steel frame. The ADSC-PGA construct was cultured for 7 days, and matrix production was examined with (C) phase-contrast microscopy (magnification, x40) and (D) scanning electron microscopy (magnification, x500). ADSCs, adipose-derived stem cells; PGA, polyglycolic acid.

$4 \mathrm{~W}$

A

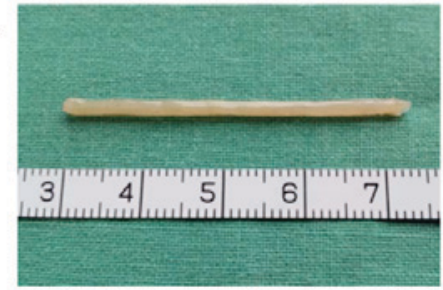

D

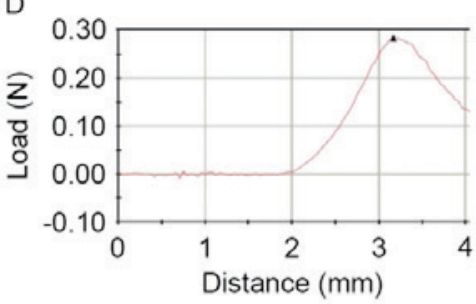

G

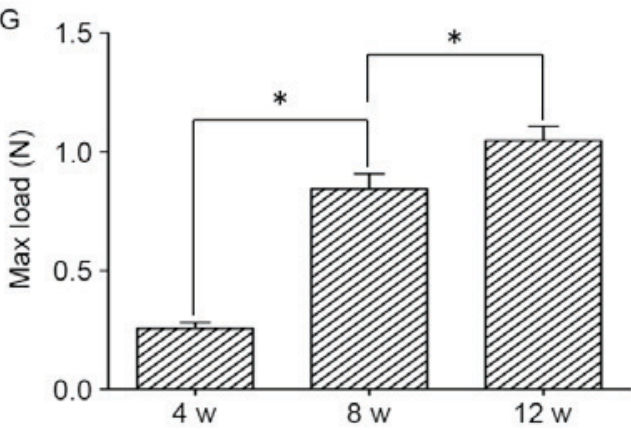

$8 \mathrm{~W}$

B
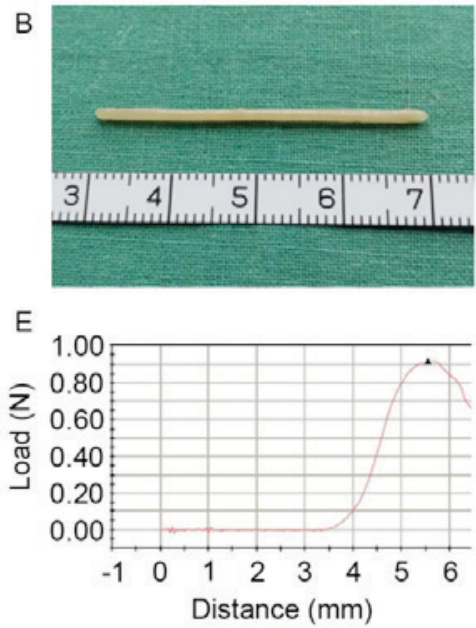

$12 \mathrm{~W}$

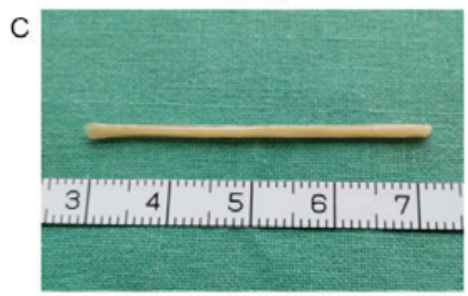

$\mathrm{F}$

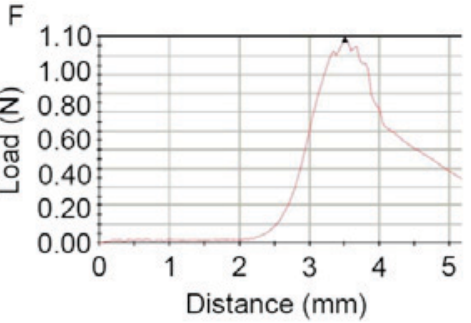

$\mathrm{H}$

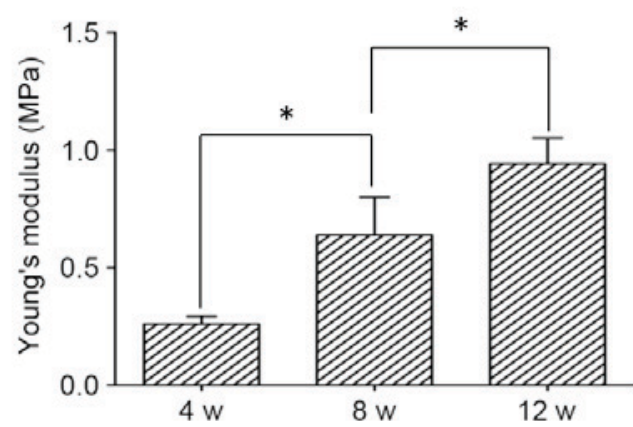

Figure 3. Gross view and mechanical property analyses of in vitro engineered slings. Gross view of the ADSC-based engineered slings cultured for (A) 4, (B) 8 and (C) 12 weeks in vitro. Representative stress/strain curves for ADSCs engineered slings at (D) 4, (E) 8 and (F) 12 weeks of culture. Comparison of the $(\mathrm{G})$ max load and $(\mathrm{H})$ Young's modulus of the engineered slings at various culture time points. " $\mathrm{P}<0.05$. ADSCs, adipose-derived stem cells; max load, maximal load. 

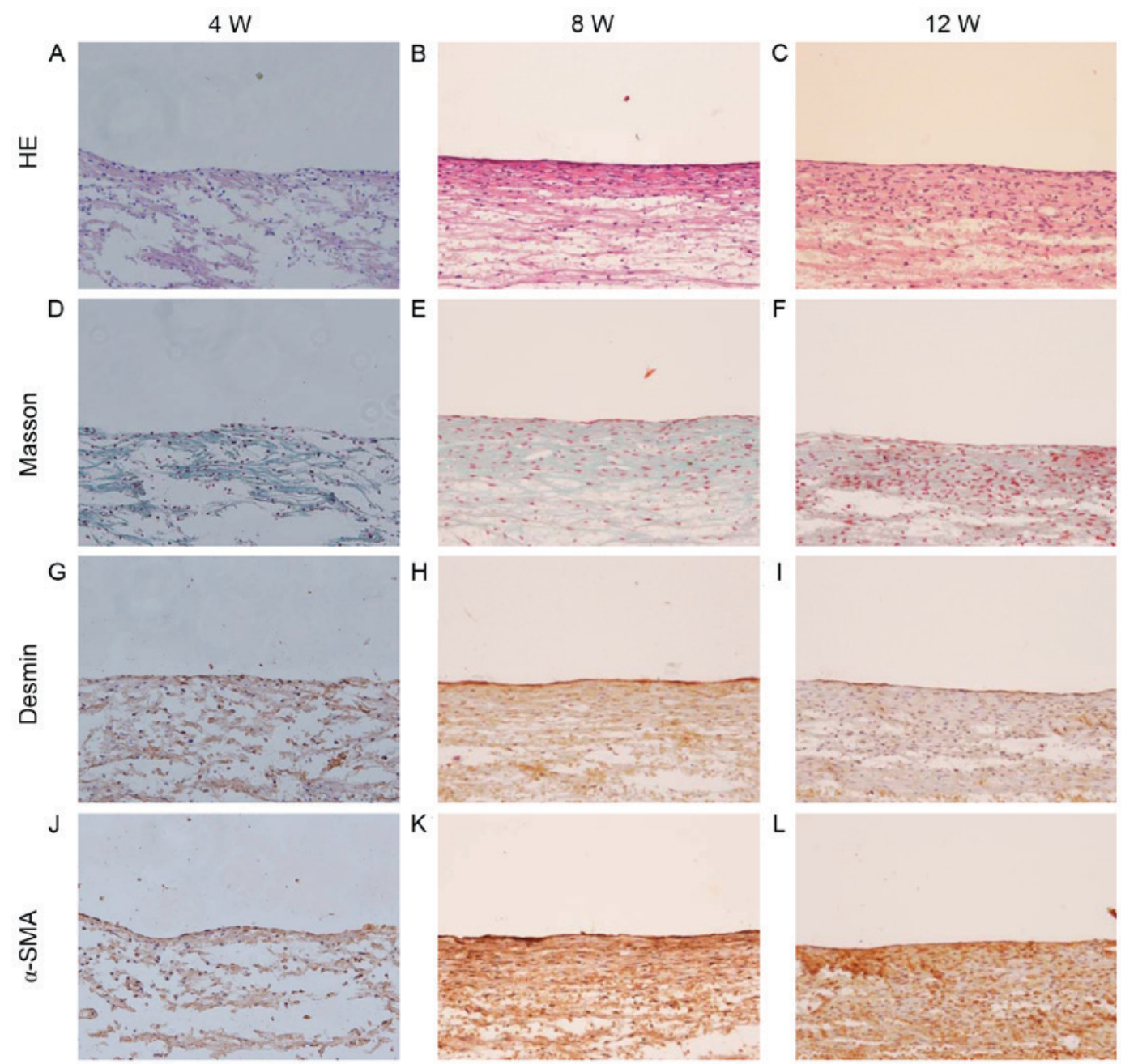

Figure 4. Histological evaluation of the tissue engineered slings. Hematoxylin and eosin staining at (A) 4, (B) 8 and (C) 12 weeks of culture. Masson staining of the in vitro engineered slings at (D) 4, (E) 8 and (F) 12 weeks of culture. Immunohistochemistry staining for desmin at (G) 4 , (H) 8 and (I) 12 weeks of culture. Immunohistochemistry staining for $\alpha$-SMA at (J) 4, (K) 8 and (L) 12 weeks of culture. Magnification, $\mathrm{x} 200 . \alpha$-SMA, $\alpha$-smooth muscle actin.

\section{Discussion}

Previous studies have reported the success of sling engineering for treating stress urinary incontinence $(7,8)$. An important issue in sling engineering is finding an appropriate cell source for engineering a transplantable sling graft. ADSCs have proven to be an excellent cell source, which have the advantage of being able to be harvested in abundance and causing fewer traumas to the donor site. Furthermore, ADSCs possess a similar pluripotency and self-renewal potential to BMSCs (23). Previously, the periurethral injection of ADSCs has been demonstrated to allow the active functional recovery of deficient sphincters $(24,25)$. Therefore, ADSCs are likely to become the primary cell source for sling engineering. PGA has been widely used in tissue engineering due to its biocompatibility and degradability. Previous studies have revealed that by forming a preliminary tissue structure PGA could substantially degrade in vitro, avoiding the accumulation of degradation products at the implantation site, which may adversely affect tissue regeneration by causing fibrosis $(26,27)$.

The present study investigated the feasibility of engineering a relatively thick sling by promoting the myoblast differentiation of ADSCs seeded onto PGA scaffolds under mechanical loading stress. This revealed that a relatively thick sling could be engineered after 12 weeks of in vitro culture. Furthermore, the engineering of a sling requires a relatively long time to allow for tissue maturation, which leads to improved mechanical properties. In the present study, the engineered sling could reach a gross diameter of $>2 \mathrm{~mm}$ and exhibited enhanced mechanical properties in a time-dependent manner. Furthermore, histological examination revealed that the collagen fibers and myoblasts were highly compacted, which increased with increased culture times, and complete degradation of the scaffold material was identified after 12 weeks of culture.

The present preliminary study demonstrated the feasibility of engineering a sling in vitro using a tissue engineering approach. The method used in the present study may aid in the future clinical treatment of SUI. In addition, following in vitro mechanical loading, the engineered sling tissue matured and demonstrated enhanced mechanical properties, which demonstrated that mechanical loading serves an important role in the maturation of tissue-engineered slings. However, there were several limitations in the present study. The tension-loaded slings were observed to be thinner with increased engineering times. Therefore, a constant strain without relief, which is non-physiological, may not be the best way to exert mechanical 
loading stress. Previous studies have demonstrated that tissue quality and mechanical strength could be markedly improved when periodic mechanical loading was applied in a bioreactor system $(28,29)$. Thus, a dynamic strain may be a more appropriate approach to pursue in future.

In conclusion, to the best of our knowledge, the present study demonstrated for the first time that a sling-like tissue structure could be generated in vitro by culturing the cell scaffold for a relatively long time. The results of the present study identified that differentiated ADSCs could maintain their myoblast phenotype when cultured on the PGA scaffold under a static strain. In addition, as engineering times increased, the engineered sling tissues exhibited a notable improvement in histological structure and mechanical properties. However, the slings under constant strain were observed to be thinner over time, and so the application of a bioreactor system to exert dynamic strain in future is warranted.

\section{Acknowledgements}

The present study was supported by the Natural Science Foundation of China (grant no. 81270780), the Youth Project of the Shanghai Municipal Commission of Health and Family Planning (grant no. 20164Y0059) and the Natural Science Foundation of Minhang (grant no. 2016MHZ37).

\section{References}

1. Abrams P, Cardozo L, Fall M, Griffiths D, Rosier P, Ulmsten U, van Kerrebroeck P, Victor A and Wein A: The standardisation of terminology of lower urinary tract function: Report from the Standardisation Sub-committee of the International Continence Society. Am J Obstet Gynecol 187: 116-126, 2002.

2. Klausner AP and Vapnek JM: Urinary incontinence in the geriatric population. Mt Sinai J Med 70: 54-61, 2003.

3. Rutner AB, Levine SR and Schmaelzle JF: Processed porcine small intestine submucosa as a graft material for pubovaginal slings: Durability and results. Urology 62: 805-809, 2003.

4. Hung MJ, Liu FS, Shen PS, Chen GD, Lin LY and Ho ES: Analysis of two sling procedures using polypropylene mesh for treatment of stress urinary incontinence. Int J Gynaecol Obstet 84: 133-141, 2004

5. Stav K, Dwyer PL, Rosamilia A, Schierlitz L, Lim YN, Chao F, De Souza A, Thomas E, Murray C, Conway C and Lee J: Repeat synthetic mid urethral sling procedure for women with recurrent stress urinary incontinence. J Urol 183: 241-246, 2010.

6. Walter AJ, Morse AN, Leslie KO, Zobitz ME, Hentz JG and Cornella JL: Changes in tensile strength of cadaveric human fascia lata after implantation in a rabbit vagina model. J Urol 169: 1907-1910, 2003

7. Kim IG, Piao S, Hong SH, Kim SW, Hwang TK, Oh SH, Lee JH and Lee JY: The effect of a bioactive tissue-engineered sling in a rat of stress incontinence model. J Biomed Mater Res A 100: 286-292, 2012

8. Zou XH, Zhi YL, Chen X, Jin HM, Wang LL, Jiang YZ, Yin Z and Ouyang HW: Mesenchymal stem cell seeded knitted silk sling for the treatment of stress urinary incontinence. Biomaterials 31: 4872-4879, 2010.

9. Lee JY, Cannon TW, Pruchnic R, Fraser MO, Huard J and Chancellor MB: The effects of periurethral muscle-derived stem cell injection on leak point pressure in a rat model of stress urinary incontinence. Int Urogynecol J Pelvic Floor Dysfunct 14: 31-37, 2003.

10. Zhao W, Zhang C, Jin C, Zhang Z, Kong D, Xu W and Xiu Y: Periurethral injection of autologous adipose-derived stem cells with controlled-release nerve growth factor for the treatment of stress urinary incontinence in a rat model. Eur Urol 59: 155-163, 2011.
11. Li GY, Zhou F, Gong YQ, Cui WS, Yuan YM, Song WD, Xin H, Liu T, Li WR, Gao ZZ, et al: Activation of VEGF and ERK1/2 and improvement of urethral function by adipose-derived stem cells in a rat stress urinary incontinence model. Urology 80: 953.e1-e8, 2012.

12. Kim SO, Na HS, Kwon D, Joo SY, Kim HS and Ahn Y: Bone-marrow-derived mesenchymal stem cell transplantation enhances closing pressure and leak point pressure in a female urinary incontinence rat model. Urol Int 86: 110-116, 2011.

13. Mitterberger M, Marksteiner R, Margreiter E, Pinggera GM, Frauscher F, Ulmer H, Fussenegger M, Bartsch G and Strasser H: Myoblast and fibroblast therapy for post-prostatectomy urinary incontinence: 1-year followup of 63 patients. J Urol 179: 226-231, 2008

14. Niklason LE, Abbott W, Gao J, Klagges B, Hirschi KK, Ulubayram K, Conroy N, Jones R, Vasanawala A, Sanzgiri S and Langer R: Morphologic and mechanical characteristics of engineered bovine arteries. J Vasc Surg 33: 628-638, 2001.

15. Zuk PA, Zhu M, Ashjian P, De Ugarte DA, Huang JI, Mizuno H, Alfonso ZC, Fraser JK, Benhaim P and Hedrick MH: Human adipose tissue is a source of multipotent stem cells. Mol Biol Cell 13: 4279-4295, 2002.

16. Arrigoni E, Lopa S, de Girolamo L, Stanco D and Brini AT: Isolation, characterization and osteogenic differentiation of adipose-derived stem cells: From small to large animal models. Cell Tissue Res 338: 401-411, 2009.

17. Wang Y, Zhao L and Hantash BM: Support of human adipose-derived mesenchymal stem cell multipotency by a poloxamer-octapeptide hybrid hydrogel. Biomaterials 31: 5122-5130, 2010

18. Wang YH, Ho ML, Chang JK, Chu HC, Lai SC and Wang GJ: Microporation is a valuable transfection method for gene expression in human adipose tissue-derived stem cells. Mol Ther 17: 302-308, 2009

19. Pittenger MF, Mackay AM, Beck SC, Jaiswal RK, Douglas R, Mosca JD, Moorman MA, Simonetti DW, Craig S and Marshak DR: Multilineage potential of adult human mesenchymal stem cells. Science 284: 143-147, 1999.

20. Chen B, Wang B, Zhang WJ, Zhou G, Cao Y and Liu W: In vivo tendon engineering with skeletal muscle derived cells in a mouse model. Biomaterials 33: 6086-6097, 2012.

21. Wang Y, Fu Q, Zhao RY and Deng CL: Muscular tubes of urethra engineered from adipose-derived stem cells and polyglycolic acid mesh in a bioreactor. Biotechnol Lett 36: 1909-1916, 2014.

22. Shen W, Chen X, Chen J, Yin Z, Heng BC, Chen W and Ouyang HW: The effect of incorporation of exogenous stromal cell-derived factor-1 alpha within a knitted silk-collagen sponge scaffold on tendon regeneration. Biomaterials 31: 7239-7249, 2010

23. Zhu Y, Liu T, Song K, Fan X, Ma X and Cui Z: Adipose-derived stem cell: A better stem cell than BMSC. Cell Biochem Funct 26: 664-675, 2008.

24. Lin G, Wang G, Banie L, Ning H, Shindel AW, Fandel TM, Lue TF and Lin CS: Treatment of stress urinary incontinence with adipose tissue-derived stem cells. Cytotherapy 12: 88-95, 2010.

25. Wu G, Song Y, Zheng X and Jiang Z: Adipose-derived stromal cell transplantation for treatment of stress urinary incontinence. Tissue Cell 43: 246-253, 2011.

26. Cao D, Liu W, Wei X, Xu F, Cui L and Cao Y: In vitro tendon engineering with avian tenocytes and polyglycolic acids: A preliminary report. Tissue Eng 12: 1369-1377, 2006.

27. Cao Y, Rodriguez A, Vacanti M, Ibarra C, Arevalo C and Vacanti CA: Comparative study of the use of poly (glycolic acid), calcium alginate and pluronics in the engineering of autologous porcine cartilage. J Biomater Sci Polym Ed 9: 475-487, 1998.

28. Xu ZC, Zhang WJ, Li H, Cui L, Cen L, Zhou GD, Liu W and Cao Y: Engineering of an elastic large muscular vessel wall with pulsatile stimulation in bioreactor. Biomaterials 29: 1464-1472, 2008.

29. Wang C, Cen L, Yin S, Liu Q, Liu W, Cao Y and Cui L: A small diameter elastic blood vessel wall prepared under pulsatile conditions from polyglycolic acid mesh and smooth muscle cells differentiated from adipose-derived stem cells. Biomaterials 31 : 621-630, 2010. 